OPEN ACCESS

Edited by:

Silvan Licher,

Erasmus Medical Center, Netherlands

Reviewed by:

Charles Doarn,

University of Cincinnati, United States Anthony Bokolo Jnr.,

Norwegian University of Science and

Technology, Norway

${ }^{*}$ Correspondence:

Soham Rej

soham.rej@mcgill.ca

tThese authors share first authorship

¥These authors share last authorship

Specialty section:

This article was submitted to Dementia and Neurodegenerative

Diseases,

a section of the journal Frontiers in Neurology

Received: 20 August 2021 Accepted: 22 November 2021 Published: 14 December 2021

Citation:

Elbaz S, Cinalioglu K, Sekhon K,

Gruber J, Rigas C, Bodenstein K,

Naghi K, Lavin P, Greenway KT, Vahia I, Rej S and Sekhon H (2021) A Systematic Review of Telemedicine for

Older Adults With Dementia During

COVID-19: An Alternative to In-person Health Services?

Front. Neurol. 12:761965

doi: 10.3389/fneur.2021.761965

\section{A Systematic Review of Telemedicine for Older Adults With Dementia During COVID-19: An Alternative to In-person Health Services?}

\author{
Sasha Elbaz ${ }^{1 \dagger}$, Karin Cinalioglu ${ }^{1 \dagger}$, Kerman Sekhon ${ }^{2}$, Johanna Gruber ${ }^{1}$, Christina Rigas ${ }^{1}$, \\ Katie Bodenstein ${ }^{1}$, Kamran Naghi ${ }^{1}$, Paola Lavin ${ }^{1,3}$, Kyle T. Greenway ${ }^{4}$, Ipsit Vahia ${ }^{5,6}$, \\ Soham Rej ${ }^{1 * \neq}$ and Harmehr Sekhon ${ }^{1,5 \neq}$ \\ ${ }^{1}$ McGill Meditation and Mind-Body Medicine Research Clinic and Geri-PARTy Research Group, Lady Davis Research \\ Institute and Jewish General Hospital, McGill University, Montreal, QC, Canada, ${ }^{2}$ Temerty Faculty of Medicine, Toronto, ON, \\ Canada, ${ }^{3}$ Douglas Mental Health University Institute, Montreal, QC, Canada, ${ }^{4}$ Department of Psychiatry, McGill University, \\ Montreal, QC, Canada, ${ }^{5}$ Technology and Aging Laboratory, McLean Hospital, Boston, MA, United States, ${ }^{6}$ Harvard Medical \\ School, Boston, MA, United States
}

Introduction: Older adults with dementia have been significantly at more risk for not receiving the care needed and for developing further mental health problems during COVID-19. Although the rise in telemedicine adoption in the healthcare system has made it possible for patients to connect with their healthcare providers virtually, little is known about its use and effects among older adults with dementia and their mental health.

Objective: This systematic review aimed to explore the use, accessibility, and feasibility of telemedicine in older adults with dementia, as well as examine the potential mental health impacts of these technologies, through reviewing evidence from studies conducted during COVID-19.

Methods: PubMed, Scopus, and Web of Science databases were searched with the following keywords: (COVID* OR SARS-CoV-2 OR Coronavirus) AND ("mental health" OR Depression OR Stress) AND (Dementia OR Multi-Infarct Dementia OR Vascular Dementia OR Frontotemporal Dementia) AND (elder OR Aging OR Aging OR Aged) AND (Telemedicine OR "Remote Consultation" OR telehealth OR technology).

Results: A total of 7 articles from Asia, Europe, and the United States were included in this review. Throughout the studies cognitive and mental health assessments (e.g., MoCA, FAST, etc.) were performed. Despite the barriers, telemedicine was noted as a feasible approach to assist individuals with dementia in connecting with their service providers and family while reducing complications related to travel (e.g., difficulty moving, traffic, distance).

Conclusions: Due to the COVID-19 pandemic, finding alternative ways to provide services to older adults with dementia through technology may continue to become more necessary as time goes on.

Keywords: telemedicine, older adults, dementia, mental health, COVID-19 


\section{INTRODUCTION}

The COVID-19 pandemic rendered older adults more vulnerable to not receiving the healthcare needed and placed those living with dementia at an even increased risk for developing other mental health symptoms due to social isolation and loneliness (1). Telemedicine, an approach that incorporates information and communication technologies in the delivery of health care services for the diagnosis, treatment, prevention, and research and evaluation in order to advance patients' health outcomes, became more widely used following the dramatic rise in and the necessity for internet-based services during the COVID-19 pandemic (2). Telemedicine has proved a viable alternative in providing individuals with appropriate services and care along with mitigating against the effects of social isolation, especially in older patients with dementia [e.g., (3)].

Telemedicine is considered an effective option while reducing cost and increasing access to care in psychiatry treatment (4). According to a national poll released by the Canadian Medical Association (5), Canadians who connected with their doctor virtually during COVID-19 reported a high level of satisfaction (91\%). Moreover, $46 \%$ of survey respondents who used virtual care would prefer a virtual method as a first point of contact with their doctor moving forward (5).

Although telemedicine is being more widely used as an effective and low-cost option, little is known about the impact of different telemedicine approaches on older adults with dementia and their mental health. Furthermore, the accessibility of telemedicine needs to be investigated as the use of beneficial technological alternatives to in-person health services may become more common post- COVID-19. This systematic review aims to explore the use, feasibility, and acceptability of telemedicine applications for older adults with dementia during the COVID-19 pandemic to address these gaps, as well as examine the potential mental health impacts of these technologies.

\section{METHODS}

\section{Search Strategy and Keywords}

This systematic review only included research articles from 2020 to October 2021. Relevant keywords and Medical Subject Headings (MeSH) were identified and searched through 3 databases: PubMed, Scopus, and Web of Science Core Collection. Quantitative, qualitative, and mixed-method articles were included. We applied the following filter within all databases: "English". In PubMed, we applied our search string within the query box marked with "All Fields". In Scopus, we applied our search string in the query box with "Article title, Abstract, Keywords". In Web of Science, we entered our search string in the query box with "All Fields" and we applied the following filter: "Open Access".

\section{Search Criteria}

PubMed, Scopus, and Web of Science databases were searched with the following keywords: (COVID* OR SARS-CoV-2 OR Coronavirus) AND ("mental health" OR Depression OR Stress)

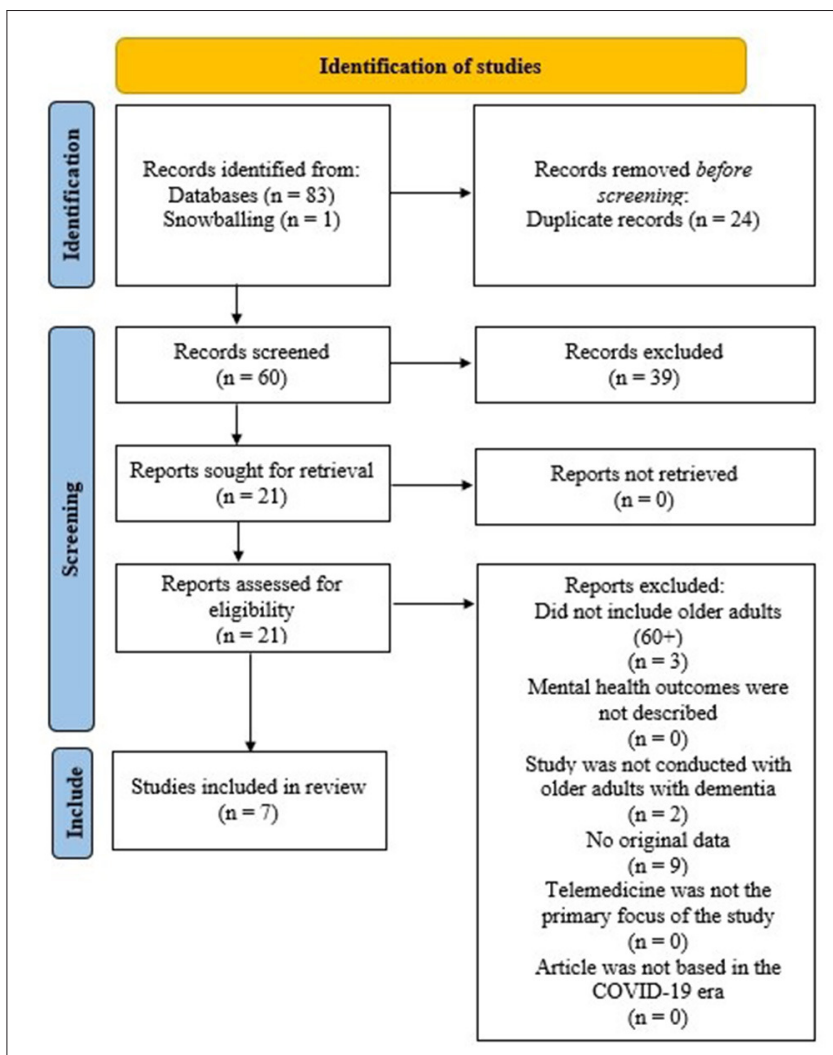

FIGURE 1 | PRISMA flow diagram illustrating the selection of the studies.

AND (Dementia OR Multi-Infarct Dementia OR Vascular Dementia OR Frontotemporal Dementia) AND (elder_ OR Aging OR Aging OR Aged) AND (Telemedicine OR "Remote Consultation" OR telehealth OR technology). The total number of number of articles across all 3 databases was 83 (PubMed: 28, Scopus: 26, and Web of Science Core Collection: 29). We also examined the references of articles to ensure we did not exclude any relevant articles (i.e., snowballing).

\section{Selection of the Studies}

Two independent reviewers (S.E.; K.C.) examined the articles and consulted with the senior researcher in the case of uncertainty (H.S.). From the combined total of the 3 databases, 83 articles were identified from the databases, of which 24 duplicates were removed and 1 article was identified via snowballing. Next, 39 articles were removed based on the titles not relating to the topic. We then assessed the abstracts of 21 articles, in which we applied the following exclusion criteria: (1) did not include older adults $(60+)$ [3 article removed], (2) mental health outcomes were not clearly described [0 article removed], (3) the study was not conducted with individuals with dementia [2 articles removed], (4) no original data [9 articles removed], (5) telemedicine was not the primary focus of the study [0 article removed], (6) article was not based in the COVID-era [0 articles removed] (total $n$ removed $=14$ ). The resulting are the 7 published works included in this systematic review. 


\section{RESULTS}

\section{Overview of Studies Included}

The Preferred Reporting Items for Systematic Reviews and Meta-Analyses (PRISMA) flow diagram illustrating the selection process of the studies is presented in Figure 1 (6). An overview of each of the seven articles included is provided in Table 1, including details on authorship, study design, the sample population, demographics, use of a control group, the aim of each study, assessments used, and important findings. Overall, the geographic locations of the studies included four studies conducted in Europe $(7,9,10,12)$, two in the United States of America $(8,11)$, and one in Asia (3). Most of the research articles focused on recruiting community-dwelling participants (3, 9-11), whereas the others recruited participants through convenience samples in clinics, hospitals, care homes, and day centers $(7,8,12)$. All studies were conducted within the COVID19 context.

Overall, only two of the seven articles included any form of control group or condition, which included participants receiving either a phone call or reduced telemedicine service (control) as compared to receiving the intervention in its full form [i.e., $(3,9)]$. One of the studies, which used a control, utilized a cross-sectional survey design in which both the intervention and control groups had to respond to a telephonebased survey (9), whereas the other study had participants divided between a weekly phone call group and a weekly phone call plus video calling group (3).

Among the seven articles, five did not use control groups. Instead, the researchers performed longitudinal, cross-over, cross-sectional, or collaborative action research designs. Articles 2 (8), 5 (10), and 7 (12), from Table 1, investigated a number of medical clinics that were in the process of examining the feasibility and implementation of technological interventions for telemedicine services. Articles 1 (7) and 6 (11), as identified in Table 1, evaluated the roles of technology in older adults with memory decline and dementia and explored the potential barriers to technology use that individuals with cognitive decline or impairment may experience. Finally, the researchers attempted to test the benefits of emerging technologies in the third (3) and fourth (9) articles. Specifically, article 3 evaluated the beneficial impacts of phone calls or phone calls plus supplementary video calling (3) and article 4 evaluated a television-based technology (9).

Several different tests and assessments were used in the studies, which included measures of mental state or cognitive ability, experience, accessibility, etc. All studies included participants aged $65+$. The majority of these studies, excluding Gately et al. (11), had both male and female participants. With regards to age, all studies, apart from Zamir et al. (12), conducted their work with adults aged at least 70 years and older, whereas the work by Zamir et al. (12) included participants aged 65 and over.

Various studies screened participants prior to the consultations. Several factors were screened for prior to participant enrolment in the respective studies, such as physical disabilities like strokes, terminal illnesses, visual impairment, motor impairment, auditory impairment, and negative affect (using the Geriatric Depression Scale [GDS]). Lai et al. (3) screened their participants to exclude individuals with a history of strokes. Goodman-Casanova et al. (9) conducted pre-screening for participants with motor, cognitive, and visual conditions that could affect the participants' use of the television-based technology. Zeghari et al. (10) also evaluated the feasibility and reliability of a mobile unit for cognitive testing and pre-screened individuals to ensure they were not presenting with significant visual or auditory limitations that could impact their participation.

\section{Cognitive and Mental Health Outcomes}

The studies used various cognitive tests, including the MiniMental State Examination (MMSE), Montreal Cognitive Assessment (MoCA), the Quality of Life in Alzheimer's Disease (QoL-AD) scale, Geriatric Depression Scale (GDS), etc., to assess the effectiveness of telemedicine. One study found significant differences in the MoCA scores of individuals with cognitive impairment receiving both telephone and video calls compared to the telephone service-only group (12). Comparatively, two other studies found no significant differences between their 2 groups, albeit with some discrepancies $(9,10)$.

Lai et al. (3) found that individuals receiving additional telemedicine video calls had significantly higher MoCA and quality of life (demonstrated through the QoL-AD) scores [MoCA: $F_{(1,58)}=17.97, p<0.001, \eta^{2}=0.24$; QoL-AD: $F_{(1,58)}=$ $5.54, p<0.05, \eta^{2}=0.09$ ]. It was also remarked that within the 4 -week period within which the study had begun, the control group's (receiving telephone calls only) MoCA scores fell by 1.83 points (3). Goodman-Casanova et al. (9), however, found no significant differences between their intervention group and control groups across all study variables, which included the GDS, MMSE, and an in-house developed survey. Comparatively, Arighi et al. (7) found no significant differences across MMSE scores from previous in-person visits to online teleconsultations. Moreover, Zeghari et al. (10) found no statistically significant differences between face-to-face and mobile testing, using two different versions of the MMSE, FAB, SVF, etc. This finding by Zeghari et al. (10) is noted as an important indicator for future implementation of mobile cognitive testing.

\section{Practitioners', Participants', and Caregivers' Technological Feedback}

Results on feedback specific to the use of technology were mixed. There were some concerns regarding the older participants' ability to access telemedicine consultations or services. For example, Arighi et al. (7) identified that 34 participants were unable to respond to their scheduled televisit due to poor connection issues. Additionally, having a young caregiver did have a significant impact on televisit success (7). This is perhaps due to the fact that the caregiver is able to support the participant with any troubleshooting. However, most of the studies [i.e., $(8,10-12)]$ did praise the implementation of technologically mediated solutions. Iyer et al. (8) explored the opinions of older adults with varying levels of cognitive impairment (based on 
TABLE 1 | Summary of the studies $(n=7)$.

\begin{tabular}{|c|c|c|c|c|c|c|c|c|c|c|}
\hline & References & Study design & Sample & Demographics & Population & Control & Aim/objectives & Other & Assessments & Conclusions \\
\hline 1) & Arighi et al. (7) & $\begin{array}{l}\text { Cross sectional/ } \\
\text { Longitudinal }\end{array}$ & 108 (>70 years) & $\begin{array}{l}51.4 \% \text { with successful } \\
\text { televisit } \\
41.2 \% \text { male with failed } \\
\text { televisit }\end{array}$ & $\begin{array}{l}\text { Patients from the } \\
\text { Alzheimer's Center of } \\
\text { the Fondazione IRCCS } \\
\text { (Italy) }\end{array}$ & No control & $\begin{array}{l}\text { To examine the issues with } \\
\text { access to/use of digital } \\
\text { technology (i.e. digital } \\
\text { divide) in older adults with } \\
\text { dementia contacted } \\
\text { through videoconferencing }\end{array}$ & & $\begin{array}{l}\text { Remote neurologist } \\
\text { consults/ } \\
\text { interviews, MMSE }\end{array}$ & $\begin{array}{l}68.5 \% \text { ( } 74 \text { patients) } \\
\text { successfully connected } \\
\text { via televisit } \\
31.5 \% \text { ( } 34 \text { patients) } \\
\text { failed to respond to the } \\
\text { televisit } \\
\text { Failure to respond to } \\
\text { televisiting due to } \\
\text { connection difficulties do } \\
\text { not access to } \\
\text { devices/Internet } \\
\text { Presence of young } \\
\text { caregiver significantly } \\
\text { influences televisit } \\
\text { success ( } p<0.001 \text {, } \\
\text { OR 5.14). }\end{array}$ \\
\hline 2) & lyer et al. (8) & Longitudinal & $43\left(M_{\text {age }}=85.5\right.$ years $)$ & $\begin{array}{l}72.1 \% \text { had degree of } \\
\text { cognitive impairment }\end{array}$ & $\begin{array}{l}\text { Older adults that } \\
\text { receive services from an } \\
\text { academic outpatient } \\
\text { geriatrics clinic (USA) }\end{array}$ & No control & $\begin{array}{l}\text { To examine the feasibility } \\
\text { and acceptability of } \\
\text { telemedicine visits in clinic } \\
\text { serving older adults with a } \\
\text { high proportion of cognitive } \\
\text { impairment }\end{array}$ & & $\begin{array}{l}\text { Face-to-face or } \\
\text { phone } \\
\text { calls interviews } \\
7 \text {-question optional } \\
\text { experience survey } \\
\text { for patients } \\
\text { or caregivers } \\
\text { 4-question survey } \\
\text { for clinical providers }\end{array}$ & $\begin{array}{l}\text { Patients and clinicians } \\
\text { responses did not differ } \\
\text { in similarity of in-person } \\
\text { visit ( } p=0.999) \text {. } \\
\text { Patients indicated } \\
\text { greater comfort with } \\
\text { using video or telephone } \\
\text { visits in the future } \\
\text { Telemedicine services } \\
\text { are appreciated for frail, } \\
\text { older adults }\end{array}$ \\
\hline 3) & Lai et al. (3) & Longitudinal & $\begin{array}{l}60 \text { [30 control and } \\
30 \text { intervention] } M_{\text {age }} \\
\text { patients with NCD = } \\
72.73 \pm 0.84 \text { years }) \\
\text { (Mage Caregivers }= \\
71.83 \pm 0.80 \text { years } \\
\end{array}$ & $\begin{array}{l}21 \text { patients in the } \\
\text { control group received } \\
\text { between } 4-8 \text { hours of } \\
\text { support by family, } 9 \\
\text { received }>8 \text { hours of } \\
\text { support } \\
15 \text { patients in the } \\
\text { intervention group } \\
\text { received between } 4-8 \\
\text { hours of support by } \\
\text { family, } 15 \text { received }>8 \\
\text { hours of support }\end{array}$ & $\begin{array}{l}\text { Convenience sample } \\
\text { of community-dwelling } \\
\text { people with cognitive } \\
\text { impairment and } \\
\text { spousal caregivers } \\
\text { through an activity day } \\
\text { center for older } \\
\text { adults (China) }\end{array}$ & Control & $\begin{array}{l}\text { To evaluate the extent to } \\
\text { which both telehealth } \\
\text { videoconferencing and } \\
\text { regular telephone calls } \\
\text { would provide benefits to } \\
\text { older adults with NCD and } \\
\text { their caregivers during } \\
\text { COVID-19 }\end{array}$ & $\begin{array}{l}\text { Older adults with } \\
\text { NCD presenting } \\
\text { with major } \\
\text { physical disabilities, } \\
\text { such as strokes } \\
\text { were excluded }\end{array}$ & $\begin{array}{l}\text { Weekly telephone } \\
\text { calls/ Weekly health } \\
\text { services via Zoom, } \\
\text { WhatsApp, } \\
\text { or Facetime. } \\
\text { Validated Chinese } \\
\text { versions of MoCA, } \\
\text { RMBPC, QoL-AD } \\
\text { SF-36v2; ZBI } \\
\text { scale, RCSES }\end{array}$ & $\begin{array}{l}\text { Additional telemedicine } \\
\text { had a significant impact } \\
\text { halting the reduction of } \\
\text { MoCA scores that was } \\
\text { shown in the } \\
\text { telephone-only group } \\
(\eta 2=0.50) \text {. } \\
\text { Improvements in } \\
\text { physical and mental } \\
\text { health of caregivers in } \\
\text { the video-conferencing } \\
\text { group but not } \\
\text { telephone-only } \\
\left(\eta^{2}=0.23-0.51\right) .\end{array}$ \\
\hline
\end{tabular}




\begin{tabular}{|c|c|c|c|c|c|c|c|c|c|c|}
\hline & References & Study design & Sample & Demographics & Population & Control & Aim/objectives & Other & Assessments & Conclusions \\
\hline 4) & $\begin{array}{l}\text { Goodman- } \\
\text { Casanova et al. } \\
\text { (9) }\end{array}$ & $\begin{array}{l}\text { Cross-sectional } \\
\text { Survey } \\
\text { Part of a larger } \\
\text { RCT }\end{array}$ & $\begin{array}{l}93\left(M_{\text {age }}=73.34\right. \\
\text { years })\end{array}$ & $\begin{array}{l}65 \% \text { of the sample were } \\
\text { women } \\
74 \% \text { were living with } \\
\text { other people }\end{array}$ & $\begin{array}{l}\text { Community dwelling } \\
\text { older adults with mild } \\
\text { cognitive } \\
\text { impairment/mild } \\
\text { dementia recruited } \\
\text { through convenience } \\
\text { sample by the } \\
\text { Biomedical Research } \\
\text { institute of Malaga } \\
\text { (Spain) }\end{array}$ & Control & $\begin{array}{l}\text { To explore the impact of } \\
\text { confinement on the health } \\
\text { and well-being of } \\
\text { community-dwelling older } \\
\text { adults with mild cognitive } \\
\text { impairment or mild } \\
\text { dementia } \\
\text { To provide television-based } \\
\text { and telephone-based } \\
\text { health and social support } \\
\text { To evaluate a } \\
\text { television-based } \\
\text { technology for older adults } \\
\text { with various forms of } \\
\text { cognitive decline }\end{array}$ & $\begin{array}{l}\text { Older adults with a } \\
\text { score of }>11 \text { on } \\
\text { the GDS, terminal } \\
\text { illness, and } \\
\text { Individuals with } \\
\text { cognitive, visual, } \\
\text { motor conditions } \\
\text { that could affect } \\
\text { the system were } \\
\text { excluded. }\end{array}$ & $\begin{array}{l}\text { GDS MMSE } \\
\text { Telephone based } \\
\text { survey with open } \\
\text { ended (qualitative) } \\
\text { and numerically } \\
\text { based (quantitative) } \\
\text { questions } \\
\text { administered by } \\
\text { health professionals }\end{array}$ & $\begin{array}{l}\text { No significant } \\
\text { differences between } \\
\text { intervention and control } \\
\text { groups across all study } \\
\text { variables }(p>0.05) \\
\text { Participants with } \\
\text { TV-AssistDem did } \\
\text { perform more memory } \\
\text { exercises than the } \\
\text { control group ( } \\
<0.001 \text { ). }\end{array}$ \\
\hline 5) & $\begin{array}{l}\text { Zeghari et al. } \\
\text { (10) }\end{array}$ & $\begin{array}{l}\text { Observational } \\
\text { cross-over }\end{array}$ & 8 ( $M_{\text {age }}=76.7$ years $)$ & 4 men; 4 women & $\begin{array}{l}\text { Community dwelling } \\
\text { participants that are } \\
\text { socially isolated (France) }\end{array}$ & No control & $\begin{array}{l}\text { To evaluate the feasibility } \\
\text { and reliability of mobile unit } \\
\text { settings for remote } \\
\text { cognitive testing }\end{array}$ & $\begin{array}{l}\text { Individuals with } \\
\text { significant vision } \\
\text { and auditory } \\
\text { problems which } \\
\text { would impact ability } \\
\text { to perceive and } \\
\text { understand the } \\
\text { clinician were } \\
\text { excluded }\end{array}$ & $\begin{array}{l}\text { Short clinical } \\
\text { interview, cognitive } \\
\text { screening tests, } \\
\text { Acceptability scale, } \\
\text { Two versions of } \\
\text { MMSE, FAB, } 5 \\
\text { words: } 5 \text { mots de } \\
\text { Dubois; SVF; PVF; } \\
\text { DS }\end{array}$ & $\begin{array}{l}\text { No significant } \\
\text { differences between } \\
\text { in-person testing vs } \\
\text { mobile testing (ps = } \\
0.115-1) \\
\text { Acceptability scores } \\
\text { revealed that all } \\
\text { participants found the } \\
\text { MU easy to access and } \\
\text { as comfortable ass } \\
\text { being face-to-face }\end{array}$ \\
\hline 6) & Gately et al. (11) & Cross-Sectional & $\begin{array}{l}24 \text { (range } \text { age }=45-\geq \\
75)\end{array}$ & $\begin{array}{l}\text { Veterans with dementia } \\
(100 \% \text { Male) } \\
\text { All participants were } \\
\text { white. } \\
\text { One caregiver had prior } \\
\text { experience with } \\
\text { teleconferencing } \\
\text { services for dementia } \\
\text { management, all } \\
\text { caregivers had } \\
\text { experience with } \\
\text { video conferencing }\end{array}$ & $\begin{array}{l}\text { Community-dwelling } \\
\text { caregivers of Veterans } \\
\text { with Dementia (USA) }\end{array}$ & No control & $\begin{array}{l}\text { To evaluate the role of } \\
\text { in-home video telehealth } \\
\text { technologies to meet the } \\
\text { needs of caregivers and } \\
\text { persons with dementia To } \\
\text { identify strategies to adapt } \\
\text { in-home video } \\
\text { telehealth services }\end{array}$ & & $\begin{array}{l}\text { Semi-structured } \\
\text { qualitative } \\
\text { interviews (approx. } \\
20 \text { minutes long) }\end{array}$ & $\begin{array}{l}\text { Caregivers describe that } \\
\text { telehealth services can } \\
\text { be beneficial as a } \\
\text { follow-up service } \\
\text { Caregivers propose that } \\
\text { one barrier technological } \\
\text { implementation for older } \\
\text { adults with dementia is } \\
\text { that they may have } \\
\text { limited ability to engage/ } \\
\text { manage the devices } \\
\text { without help }\end{array}$ \\
\hline 7) & Zamir et al. (12) & $\begin{array}{l}\text { Collaborative } \\
\text { action research } \\
\text { (CAR) }\end{array}$ & $\begin{array}{l}22 \text { older adult } \\
\text { residents ( } \geq 65 \text { years) } \\
8 \text { facilitators } \\
\text { (22-50 years) }\end{array}$ & $\begin{array}{l}7 \text { residents with } \\
\text { dementia or signs of } \\
\text { cognitive decline } \\
12 \text { residents with } \\
\text { hearing impairment } 9 \\
\text { with visual impairment } \\
3 \text { that are non-verbal } 6 \\
\text { that are frail }\end{array}$ & $\begin{array}{l}\text { Convenience sample } \\
\text { of older adults in care } \\
\text { homes (UK) }\end{array}$ & No control & $\begin{array}{l}\text { To explore the feasibility } \\
\text { and accessibility of whether } \\
\text { video-calls between care } \\
\text { homes could reduce } \\
\text { loneliness and social } \\
\text { isolation in older adults. }\end{array}$ & & $\begin{array}{l}\text { Ethnographic } \\
\text { approach } \\
\text { consisting of } \\
\text { observations, } \\
\text { informal } \\
\text { unstructured } \\
\text { feedback, memo } \\
\text { writing and } \\
\text { semi-structured } \\
\text { interviews }\end{array}$ & $\begin{array}{l}\text { Five dominant themes } \\
\text { were revealed } \\
\text { Some residents living in } \\
\text { the care home seemed } \\
\text { to have regained their } \\
\text { energy and self-purpose } \\
\text { because of the video } \\
\text { calls. Therefore, the } \\
\text { increase of the } \\
\text { residents' social } \\
\text { networks by connecting } \\
\text { them to other care home } \\
\text { residents may have } \\
\text { helped decrease } \\
\text { their loneliness }\end{array}$ \\
\hline
\end{tabular}

ologies to meet the

One caregiver had prior

teleconferencing 
Functional Assessment Staging Tool [FAST] scores) through qualitative interviews and found that although clinicians found video technology services burdensome, patients and caregivers did not. In fact, patients reported feelings of connectedness and appreciated the discussions (8). Despite their initial disdain for arduous technological implementations, the service providers were appreciative of the ability to have many family members that were across geographically different areas united to discuss the patient's health (8).

Gately et al. (11) identified that caregivers valued video telemedicine services for their ability to greatly reduce travel needs (both issues with distance and travel but also facilitating dementia-related decreases in mobility and cognition), and increase the ability of family members with physical limitations or living far away to engage in medical visits. Zeghari et al. (10) contend that remote neuropsychological testing through their mobile unit and video chat system was a feasible endeavor. This was supported by scores on an accessibility scale in which participants considered the virtual call comparable to face-toface meetings (10). Zamir et al. (12) revealed that telemedicine calls between care homes provided some residents with renewed energy and self-purpose.

\section{Barriers to Technological Adoption}

Of the seven studies included in this review, four considered the potential barriers to technological adoption for older adults living with memory decline, Alzheimer's, and dementia (i.e., $(7,8,11,12)$. Gately et al. (11) noted several barriers, including the challenges of having discussions with older adults with cognitive issues over video (due to technical issues or natural decreases in focus/attention), potential difficulties for service providers in acquiring an accurate representation of the care recipient, etc. Arighi et al. (7) proposed that lack of access to a helpful caregiver may hinder the patient's ability to properly use the technology. Similarly, Iyer et al. (8) cite difficulties such as lack of technological literacy and devices with cameras. Zamir et al. (12) identified five themes (i.e., regaining sense of self and purpose, residents with dementia remember faces not technology, inter and intra connectedness, organizational issues creating barriers to long-term implementation, and situational loneliness to overcome) all of which may create long-term barriers to implementation.

\section{DISCUSSION}

This systematic review aimed to explore the use, feasibility, and acceptability of telemedicine applications for older adults with dementia during the COVID-19 pandemic. In this systematic review, we explored seven articles implementing various forms of telemedicine projects ranging from video and telephone calling [e.g., (3, 7, 10-12)], and modification of everyday technologies such as televisions [e.g., (9)]. The findings of this systematic review clarify noteworthy developments within telemedicine research in the wake of COVID-19 delivered to older adults with dementia [e.g., refinement of remote cognitive assessments through a mobile unit (10), or developing television-based treatments that are intuitively designed for older adults with dementia (9), etc.]. Two main themes were observed: the barriers remaining to telemedicine implementation, in the wake of COVID19 and the benefits of telemedicine use during COVID-19.

Notably, COVID-19 not only led to improvements in Internet-based services but was a strong catalyst that led to the dramatic, widespread adoption of telemedicine in healthcare systems worldwide, and somehow, this approach to care fit in the notoriously conservative healthcare industry, which is typically slow to adopt novel technologies (13-16). Indeed, the elderly have become one of the predominant demographics targeted for telemedicine projects as these devices have the possibility to connect, monitor, and assist seniors with healthcare professionals, emergency services, and family members across large distances without the need for in-person, face to face, interactions (17).

As the number of telemedicine projects continues to rise in response to the pandemic, it should be noted that the group for which the technology is perhaps most imperative (i.e., older adults with cognitive decline - most at-risk for COVID-19) may not be fully equipped to use it without the proper assistance $(7,11,14)$. To begin with, the lack of knowledge and digital literacy are established causes of stress and disengagement with technology among older adults $(18,19)$. More so, older adults are typically less accustomed to technologies and may avoid them entirely (10). In this situation, a competent caregiver would play a crucial role (11). This distinction is further exemplified by Gately et al. (11), who affirm that without proper help and support, even individuals living with a mild form of dementia may have significant difficulties with using telemedicine services which would worsen as the disease progresses.

Arighi et al. (7) further noted the importance of caregiver assistance as a moderator for the success of their telemedicine intervention. Notably, it was found that when older patients received the support of younger caregivers (e.g., children or grandchildren), telemedicine consultations were significantly more successful (7). Zamir et al. (12) also posited that telemedicine approaches should be facilitated by younger care staff. The current systematic review revealed several barriers remaining within telemedicine practices applied to the geriatric population, specifically, individuals living with dementia, such as the inability to deal with technical issues, connectivity problems, as well as the loss of information due to being unable to properly examine the patient $(7,8,11,12)$.

Nevertheless, a consensus remains that telemedicine could positively impact patients and their access to healthcare [e.g., $(8,10-12)]$. This suggests that despite the current issues that older adults with dementia may face, there remains an overall positive aspect to providing services via technology. Lai et al. (3) further propose the impact of their telemedicine intervention (via video conference) to help their older participants develop a stronger resilience to the effects of COVID-19 related isolation (as shown through improvements in the intervention groups QoL-AD scores).

Moreover, in all seven studies, the older adults showed a trend toward admiration for these technologies (3, 7-12). For example, chatting with physicians via video calls was welcomed [e.g., (3, 810)] and having access to telemedicine-based television services 
resulted in increased use of memory exercise game use (9). It may also indicate that older adults are willing to engage with new technologies if they recognize the benefits of using the device and have access to the technology. This is corroborated by Heinz et al.' (20) work, whereby it was proposed that seniors' motivation to engage with technology is higher when they are able to perceive the added benefits of technology use, such as increased autonomy and a better quality of life. Overall, these findings suggest that while there may be a concern regarding older adults' ability to use telemedical services, the benefits of digital interventions could outweigh this concern. This would be possible with proper design, support, oversight from caregivers and staff, in addition to providing a greater understanding of the usefulness of these tools to older adults.

Some limitations exist within the current set of studies. For instance, few quantitative mental health assessments were included. One such example is the study by Zamir et al. (12), in which they conclude that older adults' mental states were improved, as demonstrated through their qualitative analyses. Due to the limitations of qualitative research (e.g., lack of quantification of change), adopting the use of a mixed-method design in follow-up work can broaden the exploration and integration of these findings to provide a more complete interpretation of what the participants are experiencing $(21,22)$. Additionally, the majority of the telemedicine assessment or interventions that were identified were video conference-based. Finally, the current systematic review did not examine telemedicine practices occurring pre-pandemic. Future studies could perhaps examine the evolution and changes that telemedicine has undergone since the arrival of COVID-19 and examine individuals' experiences longitudinally.

\section{REFERENCES}

1. Blazer D. Social isolation and loneliness in older adults-a mental health/public health challenge. JAMA Psychiatry. (2020) 77:990-1. doi: 10.1001/jamapsychiatry.2020.1054

2. World Health Organization. A Health Telematics Policy in Support of WHO'S Health-For-All Strategy for Global Development: Report of the WHO Group Consultation on Health Telematics 11-16 December, Geneva, 1997. World Health Organization. (1998). Available online at: https://apps.who.int/iris/ handle/10665/63857 (accessed August 4, 2021).

3. Lai FHY, Yan EWH, Yu KKY, Tsui WS, Chan DTH, Yee BK. The protective impact of telemedicine on persons with dementia and their caregivers during the COVID-19 pandemic. Am J Geriat Psychiat. (2020) 28:117584. doi: 10.1016/j.jagp.2020.07.019

4. Shore JH. Telepsychiatry: videoconferencing in the delivery of psychiatric care. Am J Psychiatry. (2013) 170:256-62. doi: 10.1176/appi.ajp.2012.12081064

5. Canadian Medical Association. What Canadians think about virtual health care. (2020). Available online at: https://www.cma.ca/sites/default/files/pdf/ virtual-care/cma-virtual-care-public-poll-june-2020-e.pdf (accessed August 4, 2021).

6. Page MJ, McKenzie JE, Bossuyt PM, Boutron I, Hoffmann TC, Mulrow CD, et al. The PRISMA 2020 statement: an updated guideline for reporting systematic reviews. BMJ. (2021) 372:1-9. doi: 10.1136/bmj.n71

7. Arighi A, Fumagalli GG, Carandini T, Pietroboni AM, De Riz MA, Galimberti D, et al. Facing the digital divide into a dementia clinic during

\section{CONCLUSIONS}

Based on the existing body of literature during COVID-19, telemedicine assessment and intervention approaches focusing on supporting older adults with dementia are presented as helpful tools. Despite the notable barriers that exist, such as those involving accessibility and digital literacy, it should be considered that telemedicine approaches and intervention remain a feasible alternative to connecting with individuals while reducing complications related to travel (e.g., difficulty moving, traffic, distance). Given the COVID-19 pandemic's international impact and the physical distancing and isolation measures it imposes, finding alternative ways to connect may continue to become more and more essential.

\section{DATA AVAILABILITY STATEMENT}

The original contributions presented in the study are included in the article/supplementary material, further inquiries can be directed to the corresponding author/s.

\section{AUTHOR CONTRIBUTIONS}

HS and SE conceived the presented idea and framework for the systematic review. SE conducted the search for articles in consultation with $\mathrm{HS}$ and made the table and completed the PRISMA diagram. SE and KC analyzed the articles in consultation with HS and drafted the manuscript. SE, KC, and HS were involved in the planning of the manuscript. KS, JG, CR, KB, KN, PL, KG, IV, and SR revised and provided feedback for the manuscript. All authors revised and approved the final manuscript.

COVID-19 pandemic: caregiver age matters. Neurol Sci. (2021) 42:124751. doi: 10.1007/s10072-020-05009-w

8. Iyer S, Mehta P, Weith J, Hoang-Gia D, Moore J, Carlson C, et al. Converting a geriatrics clinic to virtual visits during covid-19: a case study. J Primary Care Community Health. (2021) 12:1-8. doi: 10.1177/21501327211000235

9. Goodman-Casanova JM, Dura-Perez E, Guzman-Parra J, Cuesta-Vargas A, Mayoral-Cleries F. Telehealth home support during COVID-19 confinement for community-dwelling older adults with mild cognitive impairment or mild dementia: survey study. J Med Internet Res. (2020) 22:e19434. doi: 10.2196/19434

10. Zeghari R, Guerchouche R, Tran Duc M, Bremond F, Lemoine MP, Bultingaire $\mathrm{V}$, et al. Pilot study to assess the feasibility of a mobile unit for remote cognitive screening of isolated elderly in rural areas. Int J Environ Res Public Health. (2021) 60:1-14. doi: 10.3390/ijerph1811 6108

11. Gately ME, Tickle-Degnen L, McLaren JE, Ward N, Ladin K, Moo LR. Factors influencing barriers and facilitators to in-home video telehealth for dementia management. Clin Gerontol. (2021) 1-14. doi: 10.1080/07317115.2021.1930316. [Epub ahead of print].

12. Zamir S, Hennessy C, Taylor A, Jones R. Intergroup 'Skype' quiz sessions in care homes to reduce loneliness and social isolation in older people. Geriatrics. (2020) 5:1-16. doi: 10.3390/geriatrics50 40090

13. De Marchi F, Contaldi E, Magistrelli L, Cantello R, Comi C, Mazzini L. Telehealth in neurodegenerative diseases: Opportunities and challenges for 
patients and physicians. Brain Sci. (2021) 11:237. doi: 10.3390/brainsci110 20237

14. Lam $\mathrm{K}$, Lu AD, Shi Y, Covinsky KE. Assessing telemedicine unreadiness among older adults in the United States during the COVID-19 pandemic. J Am Med Assoc Internal Med. (2020) 180:1389-91. doi: 10.1001/jamainternmed.2020.2671

15. O' Reilly MF, Merghani K, Sheehan E. Virtualised care and COVID-19. Irish J Med Sci. (2021) 190:39-40. doi: 10.1007/s11845-020-02269-5

16. Wright JH, Caudill R. Remote treatment delivery in response to the COVID19 pandemic. Psychother Psychosom. (2020) 89:130-2. doi: 10.1159/000507376

17. Magdelena M, Bujnowska-Fedak MM, Grata-Borkowska U. Use of telemedicine-based care for the aging and elderly: promises and pitfalls. Smart Homecare Technol TeleHealth. (2015) 3:91-105. doi: 10.2147/SHTT.S59498

18. Abdolahi A, Bull MT, Darwin KC, Venkataraman V, Grana MJ, Dorsey ER, et al. A feasibility study of conducting the Montreal Cognitive Assessment remotely in individuals with movement disorders. Health Informatics J. (2016) 22:304-11. doi: 10.1177/1460458214556373

19. Edwards MA, Patel AC. Telemedicine in the state of Maine: a model for growth driven by rural needs. Telemed J e-Health. (2003) 9:2539. doi: 10.1089/153056203763317620

20. Heinz M, Martin P, Margrett JA, Yearns M, Franke W, Yang HI, et al. Perceptions of technology among older adults. J Gerontol Nurs. (2013) 39:4251. doi: 10.3928/00989134-20121204-04

21. Shaw RL, Larkin M, Flowers P. Expanding the evidence within evidence-based healthcare: thinking about the context, acceptability and feasibility of interventions. BMJ Evidence Med. (2014) 19:201-3. doi: 10.1136/eb-2014-101791
22. Vedel I, Kaur N, Hong QN, El Sherif R, Khanassov V, GodardSebillotte C, et al. Why and how to use mixed methods in primary health care research. Fam Pract. (2019) 36:365-8. doi: 10.1093/fampra/ cmy127

Conflict of Interest: SR receives a junior investigator salary award from the Fonds de Recherche Quebec-Santé and an investigator-initiated research grant from Satellite Healthcare (Dialysis Company) for an unrelated project.

The remaining authors declare that the research was conducted in the absence of any commercial or financial relationships that could be construed as a potential conflict of interest.

Publisher's Note: All claims expressed in this article are solely those of the authors and do not necessarily represent those of their affiliated organizations, or those of the publisher, the editors and the reviewers. Any product that may be evaluated in this article, or claim that may be made by its manufacturer, is not guaranteed or endorsed by the publisher.

Copyright (C) 2021 Elbaz, Cinalioglu, Sekhon, Gruber, Rigas, Bodenstein, Naghi, Lavin, Greenway, Vahia, Rej and Sekhon. This is an open-access article distributed under the terms of the Creative Commons Attribution License (CC BY). The use, distribution or reproduction in other forums is permitted, provided the original author(s) and the copyright owner(s) are credited and that the original publication in this journal is cited, in accordance with accepted academic practice. No use, distribution or reproduction is permitted which does not comply with these terms. 